Check for updates

Cite this: Mater. Adv., 2022, 3,592

Received 13th October 2021, Accepted 6th November 2021

DOI: 10.1039/d1ma00953b

rsc.li/materials-advances

\section{Electrocatalytic nitrogen reduction directed through the $p$-band center of boron on $\mathrm{B}_{\mathrm{SAC}} @ \mathrm{Mo}_{2} \mathrm{C} \dagger$}

\begin{abstract}
Ashakiran Maibam, (D) ${ }^{\text {ab }}$ Sailaja Krishnamurty (D) *ab and Manzoor Ahmad Dar (D) *c
Greener modes of ammonia synthesis via the electrocatalytic route have been investigated on pristine and defective $\mathrm{Mo}_{2} \mathrm{C}$ based monolayers anchored with metal-free boron atom catalysts. Boron single atom catalysts (SACs) on the defective $\mathrm{Mo}_{2} \mathrm{C}$ monolayer has been found to activate $\mathrm{N}_{2}$ strongly with an adsorption energy of $-1.92 \mathrm{eV}$ and reduce it to $\mathrm{NH}_{3}$ efficiently with a significantly low overpotential of $0.41 \mathrm{eV}$. The exothermic adsorption of $\mathrm{N}_{2}$ and low overpotential for the nitrogen reduction reduction (NRR) appertain to the p-band center of the boron atom catalyst and charge transfer between the adsorbed $\mathrm{N}_{2}$ and the catalyst, respectively. This work brings forth the correlation between electron occupancy on the boron center and NRR catalytic efficiency on a metal-free SACs $\mathrm{AMO}_{2} \mathrm{C}$ monolayer couple, thereby serving as a lead in designing metal free electrocatalysts for the NRR.
\end{abstract}

\section{Introduction}

With the rise in global temperature and greenhouse gas emissions, most industrial processes aim to achieve carbon neutrality. However, one process with an extremely high carbon footprint accounting for $6 \%$ of global $\mathrm{CO}_{2}$ emissions and the consumption of approximately $1-2 \%$ of global energy ${ }^{1}$ is the Haber-Bosch ${ }^{2}$ ammonia synthesis process. With ammonia being an irreplaceable precursor in agriculture, various industries and energy applications, ${ }^{3,4}$ there is an urgent need to develop greener techniques for $\mathrm{NH}_{3}$ synthesis through photocatalytic, electrocatalytic or photo-electrocatalytic routes to meet the current demands. ${ }^{5,6}$ The optimal goal towards achieving ammonia economy is to develop a catalyst that reduces $\mathrm{N}_{2}$ to $\mathrm{NH}_{3}$ under ambient conditions like the nitrogenase enzyme. The electrocatalytic route of nitrogen fixation is an attractive alternative owing to its efficiency and environment-friendly nature. ${ }^{7,8}$ However, with $\mathrm{N}_{2}$ being a highly stable molecule with a $\mathrm{N}-\mathrm{N}$ triple bond energy of $940 \mathrm{~kJ} \mathrm{~mol}^{-1}$, the kinetics associated with the electrocatalytic nitrogen reduction reaction (NRR) are sluggish and the faradaic efficiency is low. ${ }^{7}$ As a

\footnotetext{
${ }^{a}$ Physical and Materials Division, CSIR-National Chemical Laboratory, Pune 411 008, India. E-mail: sailaja.raaj@gmail.com

${ }^{b}$ Academy of Scientific and Innovative Research, CSIR-Human Resource Development Centre (CSIR-HRDC) Campus, Postal Staff College area, Gaziabad, 201 002, Uttar Pradesh, India

'Department of Chemistry, Islamic University of Science and Technology, Awantipora, Jammu and Kashmir 192122, India.

E-mail:manzoor.dar@islamicuniversity.edu.in

$\dagger$ Electronic supplementary information (ESI) available. See DOI: 10.1039/d1ma00953b
}

result, the competing hydrogen evolution reaction (HER) is usually preferred over the sluggish NRR. Therefore, it is essential to design new and smart materials with high electrical conductivity that have the capability to subjugate the HER and enhance the NRR. Several scarce metals such as $\mathrm{Ru},{ }^{9,10} \mathrm{Au}^{11,12}$ and $\mathrm{Pd}^{13,14}$ have been reported as highly efficient electrocatalysts for the NRR with faradaic efficiencies of up to $36.6 \%,{ }^{13}$ their cost and availability are issues that cannot be overcome. Hence, identifying cost effective electrocatalysts based on earth abundant metals such as $\mathrm{Mo}, \mathrm{Fe}$, and $\mathrm{Co}$, etc. as potential alternatives for the NRR is the need of the hour. ${ }^{15}$

Notably, Mo metal is present as an active centre in nitrogenase enzymes, and possesses the requisite electronic structure to capture $\mathrm{N}_{2}$ molecules and has been extensively studied for the NRR. ${ }^{16}$ Several other Mo-based two-dimensional (2D) materials, nanoparticles and nanoclusters, single atom catalysts (SACs) and organometallic complexes have been reported as efficient catalysts for the NRR. ${ }^{17-26}$ While Mo-containing organic and inorganic complexes efficiently adsorb and form stable dinitrogen complexes, their application as electrocatalysts or electrodes are not warranted. ${ }^{18}$ Mo clusters and SACs, on the other hand, require a conducting/semi-conducting support for further usage as electrocatalysts. ${ }^{19,20,22,27}$ In this regard, Mo-based 2D materials such as $\mathrm{MoS}_{2},{ }^{24,28-31}$ MXenes $\left(\mathrm{Mo}_{2} \mathrm{C}\right)^{32-34}$ and MBenes $\left(\mathrm{Mo}_{2} \mathrm{~B}_{2}\right)^{35,36}$ are appealing electrocatalysts owing to their high electrical conductivity and the presence of active Mo metal centres. These 2D materials not only show high hydrophilicity, stability and conductivity but are interesting from the catalytic aspect of nitrogen reduction as the Mo metal is accessible to the nitrogen molecule. Compared 
to MBenes, MXenes have been extensively investigated experimentally for the electrocatalytic NRR. ${ }^{32,37-39}$

While computational studies on the electrochemical applications of $\mathrm{Mo}_{2} \mathrm{C}$ based $2 \mathrm{D}$ materials have been extensively carried out, they have rarely been explored for the electrocatalytic NRR. One notable study on the electrocatalytic application of $\mathrm{Mo}_{2} \mathrm{C}$ for the NRR was made recently by Zhang et al. wherein $\mathrm{Mo}_{2} \mathrm{C}$ monolayers were investigated for the NRR through density functional theory (DFT) calculations. ${ }^{34}$ It would be imperative to recollect that effective strategies to fine tune and improve the $\mathrm{N}_{2}$ binding efficacy on a $2 \mathrm{D}$ monolayer are structural modifications and incorporating active atomic centers on it. ${ }^{40}$ Thereby, pristine and defective $\mathrm{Mo}_{2} \mathrm{C}$ monolayers coupled with a metal free single atom catalyst, in particular boron, are expected to enhance the $\mathrm{N}_{2}$ adsorption and inherently improve the NRR process. Several experimental and computational studies have reported boron based metal free catalysts on 2D materials to remarkably augment the electrocatalytic NRR by promoting $\mathrm{N}_{2}$ adsorption and inhibiting the HER. ${ }^{41-43}$ The boron center behaves as a Lewis acid with empty p-orbitals, thereby resulting in a strong $\pi-\pi^{*}$ interaction with $\mathrm{N}_{2}$ and less energy demanding subsequent protonation steps for the NRR. ${ }^{44,45}$

The correlation between charge transfer from the catalytic center and nitrogen reduction efficacy is one aspect of paramount importance that has not been explored to date. Thus, in the present work, we conducted a comprehensive investigation to provide a complete picture concerning the fundamental understanding of nitrogen activation and reduction on active boron atoms anchored on a pristine $\mathrm{Mo}_{2} \mathrm{C}$ monolayer. Specifically, the coupling effect of boron single atom catalysts with defects on the $\mathrm{Mo}_{2} \mathrm{C}$ monolayer and its influence on nitrogen activation and reduction was thoroughly investigated. The p-band center and electronic structure of $2 \mathrm{D} \mathrm{Mo}_{2} \mathrm{C}$ monolayers upon the anchoring of non-metallic boron atoms directly influences their NRR catalytic efficiency. Based on our results, we found that a single boron atom catalyst anchored on a defective $\mathrm{Mo}_{2} \mathrm{C}$ monolayer can effectively produce $\mathrm{NH}_{3}$ with a record low overpotential of $0.41 \mathrm{eV}$.

\section{Computational details}

All DFT calculations were carried out with the Vienna $a b$ initio Simulation Package (VASP). ${ }^{46}$ The generalized gradient approximation (GGA) and the Perdew-Burke-Ernzerhof (PBE) ${ }^{47}$ functional has been employed with an energy cutoff of $532 \mathrm{eV}$ to describe all electron core-interactions. A DFT-D3 correction method has been incorporated to account for the long-range van der Waals (vdW) interactions. ${ }^{48}$ All the catalyst systems sampled with a $(5 \times 5 \times 1)$ Monkhorst-Pack k-point grid and a vacuum space of $20 \AA$ along the $Z$-direction are relaxed until the atomic energy and forces converge to $10^{-5} \mathrm{eV}$ per atom and $0.005 \mathrm{eV} \AA^{-1}$, respectively. For the density of states and electronic structure calculations, a higher $(11 \times 11 \times 1)$ MonkhorstPack k-point grid has been employed.
The stability of atomic boron catalysts on $\mathrm{Mo}_{2} \mathrm{C}$ and its analogues is evaluated in terms of binding energy, $E_{\mathrm{b}}$ which is calculated by using the equation,

$$
E_{\mathrm{b}}=\left(E_{\mathrm{B}_{\mathrm{cat}} @ \mathrm{Mo}_{2} \mathrm{C}}\right)-\left(E_{\mathrm{Mo}_{2} \mathrm{C}}\right)-\left(E_{\mathrm{B}_{\mathrm{cat}}}\right)
$$

where, $E_{\mathrm{B}_{\mathrm{cat}} @ \mathrm{Mo}_{2} \mathrm{C}}$ and $E_{\mathrm{Mo}_{2} \mathrm{C}}$ are the total electronic energies of the $2 \mathrm{D} \mathrm{Mo}_{2} \mathrm{C}$ monolayer with and without atomic boron catalysts and $E_{\text {Bcat }}$ is the electronic energy of atomic boron. The adsorption of $\mathrm{N}_{2}$ on the $2 \mathrm{D} \mathrm{Mo}_{2} \mathrm{C}$ monolayer has been computed for the parallel and perpendicular modes and the efficiency of these materials to chemisorp $\mathrm{N}_{2}$ molecule has been calculated in terms of the $\mathrm{N}_{2}$ adsorption energy, $\left(E_{\mathrm{ads}}\right)$ as given below,

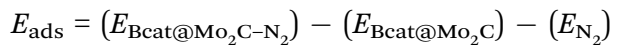

where, $E_{\mathrm{Bcat}} \mathrm{Mo}_{2} \mathrm{C}-\mathrm{N}_{2}, E_{\mathrm{Bcat} @ \mathrm{Mo}_{2} \mathrm{C}}$ and $E_{\mathrm{N}_{2}}$ are the total electronic energies of $\mathrm{N}_{2}$ adsorbed systems, $\mathrm{B}_{\text {cat }} @ \mathrm{Mo}_{2} \mathrm{C}$ and free $\mathrm{N}_{2}$ molecules, respectively.

The Gibbs free energy change, $\Delta \mathrm{G}$ in every protonation step of the NRR has been calculated by employing the computational SHE (standard hydrogen electrode) model proposed by Nørskov et al. ${ }^{49}$ using the equation,

$$
\Delta G=\Delta E+\Delta \mathrm{ZPE}-T \Delta S
$$

where, $\Delta E$ is the change in electronic energy, $\triangle \mathrm{ZPE}$ is the change in zero-point energy, $T$ is the room temperature (298.15 K) and $\Delta S$ is the change in entropy. The zero-point energies and entropy contributions are calculated by considering the vibrational frequencies of the adsorbed gas phase species. Furthermore, the overpotential for the electrocatalytic NRR on the $\mathrm{Mo}_{2} \mathrm{C}$ monolayer and its analogues has been calculated as $\eta=U_{\mathrm{SHE}}-U_{\mathrm{PDS}}$, where $U_{\mathrm{SHE}}=-0.16 \mathrm{eV}$, is the standard reduction potential of $\mathrm{N}_{2}$ to $\mathrm{NH}_{3}$ and $U_{\mathrm{PDS}}=\Delta G_{\mathrm{max}} / \mathrm{e}$ for the NRR pathway.

\section{Results and discussion}

\section{1 $\mathrm{N}_{2}$ adsorption on $\mathrm{B}_{\text {cat }} \mathrm{Mo}_{2} \mathrm{C}$}

The stability of atomic boron catalysts on $\mathrm{Mo}_{2} \mathrm{C}$ is one of the fundamental prerequisites for their implementation as electrocatalysts for the NRR. Boron has been anchored on conventional pristine $1 \mathrm{~T}-\mathrm{Mo}_{2} \mathrm{C}$ as a single atom catalyst (SAC) or a diatom catalyst (DAC), respectively referred to as $\mathrm{B}_{\mathrm{SAC}} @ \mathrm{Mo}_{2} \mathrm{C}$ and $\mathrm{B}_{\mathrm{DAC}} @ \mathrm{Mo}_{2} \mathrm{C}$ from now onwards. The geometric structures of the $\mathrm{B}_{\mathrm{SAC}} @ \mathrm{Mo}_{2} \mathrm{C}$ and $\mathrm{B}_{\mathrm{DAC}} @ \mathrm{Mo}_{2} \mathrm{C}$ catalysts are presented in Fig. $\mathrm{S} 2$ (see the ESI $\dagger$ ). Anchoring $\mathrm{B}_{\mathrm{DAC}}$ on $\mathrm{Mo}_{2} \mathrm{C}$ was found to be more feasible with a binding energy of $-7.07 \mathrm{eV}$ as compared to $\mathrm{B}_{\mathrm{SAC}}(-6.90 \mathrm{eV})$. The $2 \mathrm{D} \mathrm{Mo}_{2} \mathrm{C}$ monolayer was then subjected to two major surface modifications: a Mo-vacancy and defective $\mathrm{Mo}_{2} \mathrm{C}$ with non-metal dopants as shown in Fig. $1 . \mathrm{Mo}_{2} \mathrm{C}$ with a vacant Mo-site is referred to as $\mathrm{Mo}_{2} \mathrm{C}-\mathrm{Mo}_{\text {vac }}$ and defective $\mathrm{Mo}_{2} \mathrm{C}$ obtained by replacing one Mo atom from the surface with metal-free dopants is designated as $\mathrm{Mo}_{2} \mathrm{C}-\mathrm{X}_{\text {def }}$, where $\mathrm{X}=\mathrm{B}$, $\mathrm{C}, \mathrm{N}, \mathrm{P}$ and $\mathrm{S}$. On these Mo-vacant and defective analogues of $\mathrm{Mo}_{2} \mathrm{C}$, we next adsorbed $\mathrm{B}$ single atoms to create a metal-free 


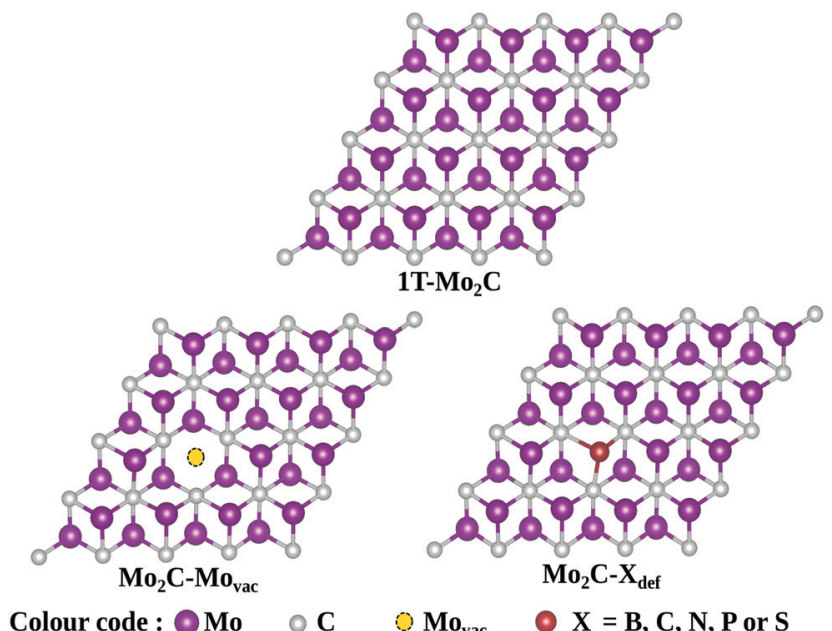

Colour code : $\odot \mathrm{Mo} \odot \mathrm{C} \quad \mathrm{Mo}_{\mathrm{vac}} \odot \mathrm{X}=\mathrm{B}, \mathrm{C}, \mathrm{N}, \mathrm{P}$ or $\mathrm{S}$

Fig. 1 The model 2D $1 \mathrm{~T}-\mathrm{Mo}_{2} \mathrm{C}$ monolayer with surface modifications considered in this study.

catalyst couple for nitrogen activation and reduction. The binding energy of $\mathrm{B}_{\mathrm{SAC}}$ ranges from $-5.35 \mathrm{eV}$ on the $\mathrm{Mo}_{2} \mathrm{C}-$ $\mathrm{Mo}_{\mathrm{vac}}$ catalyst to $-6.25 \mathrm{eV},-5.37 \mathrm{eV},-7.92 \mathrm{eV},-5.81 \mathrm{eV}$ and $-4.77 \mathrm{eV}$ respectively, on the $\mathrm{Mo}_{2} \mathrm{C}-\mathrm{B}_{\mathrm{def}}, \mathrm{Mo}_{2} \mathrm{C}-\mathrm{C}_{\mathrm{def}}, \mathrm{Mo}_{2} \mathrm{C}-$ $\mathrm{N}_{\mathrm{def}}, \mathrm{Mo}_{2} \mathrm{C}-\mathrm{P}_{\mathrm{def}}$ and $\mathrm{Mo}_{2} \mathrm{C}-\mathrm{S}_{\mathrm{def}}$ catalysts. The exothermic binding energies of the boron atom catalysts on all $\mathrm{Mo}_{2} \mathrm{C}$ analogues illustrates the stability of the boron SAC integrated on the defective $\mathrm{Mo}_{2} \mathrm{C}$ monolayers.

We next investigated the $\mathrm{N}_{2}$ adsorption efficacy and electronic properties of the $\mathrm{B}_{\mathrm{cat}} @ \mathrm{Mo}_{2} \mathrm{C}$ catalysts through the d-band centre of Mo, the p-band centre of $\mathrm{B}$ and the projected density of states (PDOS) with reference to pristine 1T- $\mathrm{Mo}_{2} \mathrm{C}$. Fig. 2 highlights the $\mathrm{N}_{2}$ adsorption energies of the $\mathrm{B}_{\mathrm{cat}} @ \mathrm{Mo}_{2} \mathrm{C}$ catalysts with reference to $1 \mathrm{~T}-\mathrm{Mo}_{2} \mathrm{C}$ and the correlation between $\mathrm{N}_{2}$ adsorption with the d-band center of Mo and the p-band center of B. $\mathrm{B}_{\mathrm{SAC}} @ \mathrm{Mo}_{2} \mathrm{C}$ and $\mathrm{B}_{\mathrm{DAC}} @ \mathrm{Mo}_{2} \mathrm{C}$ exhibit a lower exothermic

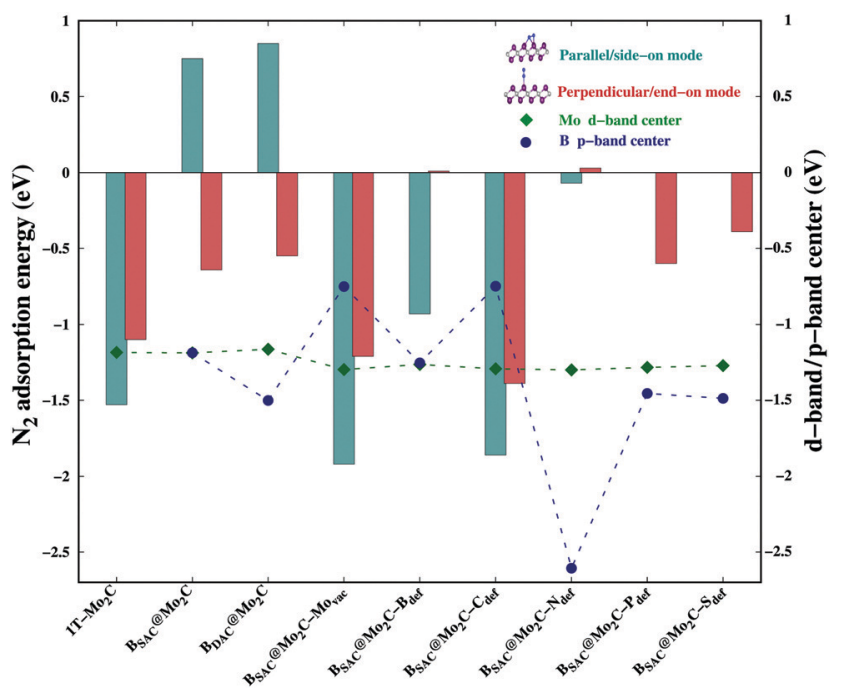

Fig. $2 \mathrm{~N}_{2}$ adsorption energies in different modes, and the Mo d-band center and $\mathrm{B} p$-band center on different $\mathrm{B}_{\text {cat }} \mathrm{aMO}_{2} \mathrm{C}$ catalysts. end-on mode of dinitrogen adsorption with $E_{\text {ads }}$ values of $-0.64 \mathrm{eV}$ and $-0.55 \mathrm{eV}$, respectively with respect to $-1.10 \mathrm{eV}$ on $1 \mathrm{~T}-\mathrm{Mo}_{2} \mathrm{C}$. It can also be noted that there are no significant changes in the Mo d-band center when $\mathrm{B}_{\mathrm{SAC}}$ and $\mathrm{B}_{\mathrm{DAC}}$ are anchored on $\mathrm{Mo}_{2} \mathrm{C}$, however the $\mathrm{B}$ p-center on $\mathrm{B}_{\mathrm{SAC}} @ \mathrm{Mo}_{2} \mathrm{C}$ is more positive than that of $\mathrm{B}_{\mathrm{DAC}} @ \mathrm{Mo}_{2} \mathrm{C}$. A more positive $\mathrm{B}$ p-band center infers that the $\mathrm{B}$ p-orbitals are closer to the Fermi level $\left(E_{\mathrm{F}}=0 \mathrm{eV}\right)$, which in turn leads to the feasible adsorption of $\mathrm{N}_{2}$. Generating a Mo-vacancy on the $\mathrm{Mo}_{2} \mathrm{C}$ monolayer leads to a less positive Mo d-band center, but in contrast, the $\mathrm{B}$ p-band becomes more positive, which in turns leads to higher chemisorption ( $-1.92 \mathrm{eV}$ ) of $\mathrm{N}_{2}$ on $\mathrm{B}_{\mathrm{SAC}} @ \mathrm{Mo}_{2} \mathrm{C}-$ $\mathrm{Mo}_{\text {vac }}$. Moreover, on analysing the Bader charges on the $\mathrm{B}_{\mathrm{cat}}$ centers, all the $\mathrm{B}_{\mathrm{cat}}$ centers are found to be negatively charged, thereby implying that there is a charge transfer from the $\mathrm{Mo}_{2} \mathrm{C}$ monolayer to $\mathrm{B}$. The only exception being the $\mathrm{B}_{\mathrm{SAC}} @ \mathrm{Mo}_{2} \mathrm{C}-\mathrm{N}_{\mathrm{def}}$ and $\mathrm{B}_{\mathrm{SAC}} @ \mathrm{Mo}_{2} \mathrm{C}-\mathrm{S}_{\mathrm{def}}$ systems with positively charged or nearly neutral $B_{\text {cat }}$ centers, respectively. Interestingly, these two systems possess a more negative $\mathrm{B}$ p-band center as compared to the rest of the systems, and thereby show lower exothermic $\mathrm{N}_{2}$ adsorption. It is also important to note that a higher exothermic $\mathrm{N}_{2}$ adsorption is not only influenced by the B p-band center but also by a more pronounced overlap between the $\pi$ orbitals of the $\mathrm{B}$ and $\mathrm{N}$ atoms. The parallel/side-on mode of $\mathrm{N}_{2}$ adsorption involves two B-N bonds, and results in two peaks in the PDOS plot (inset) with a greater electron density overlap (see Fig. 3(a)) compared to a single $\mathrm{B}-\mathrm{N}$ bond for the perpendicular/ end-on mode of $\mathrm{N}_{2}$ adsorption (Fig. 3(b)) on $\mathrm{B}_{\mathrm{SAC}} @ \mathrm{Mo}_{2} \mathrm{C}-$ $\mathrm{Mo}_{\text {vac. }}$ The $\mathrm{B}_{\mathrm{SAC}} @ \mathrm{Mo}_{2} \mathrm{C}-\mathrm{X}_{\text {def }}$ catalysts follow a similar pattern of $\mathrm{N}_{2}$ adsorption. For instance, $\mathrm{B}_{\mathrm{SAC}} @ \mathrm{Mo}_{2} \mathrm{C}-\mathrm{C}_{\mathrm{def}}$ with a more positive $\mathrm{B}$ p-band center exhibits better chemisorption of $\mathrm{N}_{2}$ when compared to $\mathrm{B}_{\mathrm{SAC}} @ \mathrm{Mo}_{2} \mathrm{C}-\mathrm{N}_{\text {def }}$ with a highly negative p-band center of B. It can be established that the adsorption and activation of $\mathrm{N}_{2}$ is influenced by the p-band center of $\mathrm{B}_{\text {cat }}$ on the $\mathrm{B}$-anchored $\mathrm{Mo}_{2} \mathrm{C}$ catalysts. Interestingly, it was noticed that the $\mathrm{N}_{2}$ chemisorption efficacy of $\mathrm{B}_{\mathrm{SAC}}$ with a Mo-vacancy is on a par with that of $\mathrm{B}_{\mathrm{SAC}}$ with C-defective $\mathrm{Mo}_{2} \mathrm{C}$, while the rest of the non-metals, i.e. $\mathrm{B}, \mathrm{P}, \mathrm{S}$ and $\mathrm{N}$ show moderate to minimal adsorption of $\mathrm{N}_{2}$. Apart from the $\mathrm{B}$ p-band center, the $\mathrm{N}_{2}$ adsorption trends could also be rationalized in terms of electronic properties such as charge difference density (CDD) and the PDOS plots provided in Fig. S3 of the ESI. $\uparrow$ The PDOS plots also show the very interesting phenomenon of a synergistic effect between the $\mathrm{C}$ from the $\mathrm{Mo}_{2} \mathrm{C}$ and $\mathrm{B}_{\text {cat }}$ centers. The systems that show a higher exothermic $\mathrm{N}_{2}$ adsorption, in turn show a more pronounced overlap between the $\mathrm{C}$ p-orbitals and $\mathrm{B}$ p-orbitals, thus the synergistic effect of $\mathrm{C}$ and $\mathrm{B}$ enhances the $\mathrm{N}_{2}$ adsorption efficiency in the $\mathrm{B}_{\mathrm{cat}} @ \mathrm{Mo}_{2} \mathrm{C}$ catalysts.

\section{$3.2 \quad \mathrm{~N}_{2}$ reduction on $\mathrm{B}_{\text {cat }} @ \mathrm{Mo}_{2} \mathrm{C}$ catalysts}

Finally we explored the thermodynamics for the reduction of $\mathrm{N}_{2}$ to $\mathrm{NH}_{3}$ on the $\mathrm{B}_{\mathrm{cat}} @ \mathrm{Mo}_{2} \mathrm{C}$ catalysts that showed strong exothermic $\mathrm{N}_{2}$ chemisorption. Also the NRR pathways on $\mathrm{B}_{\mathrm{SAC}} @ \mathrm{Mo}_{2} \mathrm{C}$ and $\mathrm{B}_{\mathrm{DAC}} @ \mathrm{Mo}_{2} \mathrm{C}$ were analysed to deduce whether the role of a second $\mathrm{B}$ atom enhances or inhibits the reduction process. Among the defective monolayers with surface modification, 

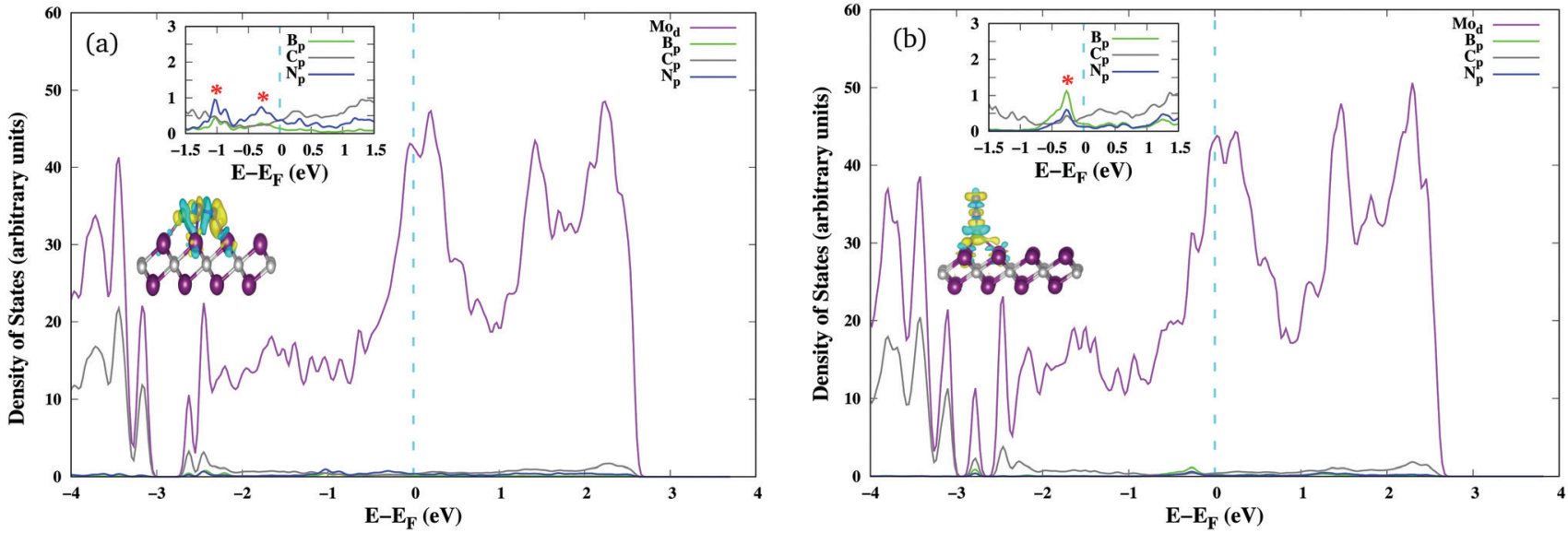

Fig. 3 PDOS of $\mathrm{N}_{2}$ adsorbed on $\mathrm{B}_{\mathrm{SAC}} @ \mathrm{MO}_{2} \mathrm{C}-\mathrm{Mo}_{\mathrm{vac}}$ with the insets showing hybridisation of the $\mathrm{N}$-orbitals and $\mathrm{B}$-orbitals and the $\mathrm{CDD}$ plot generated isosurface density set to 0.003 e $\AA^{-3}$. (a) PDOS and CDD plots of $\mathrm{N}_{2}$ adsorbed on $\mathrm{B}_{\mathrm{SAC}}\left(\mathrm{aMO}_{2} \mathrm{C}-\mathrm{Mo}_{\mathrm{vac}}\right.$ via the parallel/side-on mode. (b) PDOS and $\mathrm{CDD}$ plots of $\mathrm{N}_{2}$ adsorbed on $\mathrm{B}_{\mathrm{SAC}}\left(\mathrm{MMO}_{2} \mathrm{C}-\mathrm{MO}_{\mathrm{vac}}\right.$ via the perpendicular/end-on mode.

$\mathrm{B}_{\mathrm{SAC}} @ \mathrm{Mo}_{2} \mathrm{C}-\mathrm{Mo}_{\mathrm{vac}}$ and $\mathrm{B}_{\mathrm{SAC}} @ \mathrm{Mo}_{2} \mathrm{C}-\mathrm{C}_{\mathrm{def}}$ were considered as both showed highly exothermic chemisorption of dinitrogen in both the parallel as well as the perpendicular mode. Previous studies have revealed that the reduction of $\mathrm{N}_{2}$ can proceed via three pathways, viz. distal or alternating and enzymatic, respectively, for $\mathrm{N}_{2}$ adsorbed in the perpendicular and parallel modes. On the $\mathrm{B}_{\mathrm{SAC}} @ \mathrm{Mo}_{2} \mathrm{C}$ and $\mathrm{B}_{\mathrm{DAC}} @ \mathrm{Mo}_{2} \mathrm{C}$ catalysts with $\mathrm{N}_{2}$ adsorbed preferentially in an end-on mode, the NRR pathway was explored through the distal and alternating routes as shown in Fig. S4 and S5 of the ESI. $\dagger$ The last protonation step, i.e. ${ }^{*} \mathrm{NH}_{2} \rightarrow{ }^{*} \mathrm{NH}_{3}$ has been found to be the potential determining step (PDS) for nitrogen reduction on $\mathrm{B}_{\mathrm{SAC}} @ \mathrm{Mo}_{2} \mathrm{C}$ and $\mathrm{B}_{\mathrm{DAC}} @ \mathrm{Mo}_{2} \mathrm{C}$ for both the distal and alternating route with a $\Delta G_{\max }$ of $1.10 \mathrm{eV}$ and $0.90 \mathrm{eV}$, respectively. The corresponding overpotentials, $\eta$ for reducing nitrogen to ammonia on the two catalysts are therefore, $0.94 \mathrm{eV}$ and $0.74 \mathrm{eV}$, respectively. It would be interesting to note that $\mathrm{B}_{\mathrm{SAC}} @ \mathrm{Mo}_{2} \mathrm{C}$, which is more exergonic towards $\mathrm{N}_{2}(-0.15 \mathrm{eV})$ as compared to $\mathrm{B}_{\mathrm{SAC}} @ \mathrm{Mo}_{2} \mathrm{C}$ $(-0.05 \mathrm{eV})$ follows a more uphill first protonation step $(0.21 \mathrm{eV})$ and a complementary more uphill PDS. For the $\mathrm{B}_{\mathrm{SAC}} @ \mathrm{Mo}_{2} \mathrm{C}-$ $\mathrm{Mo}_{\text {vac }}$ monolayer with one Mo-atom vacancy that shows exothermic $\mathrm{N}_{2}$ adsorption in the side-on as well as end-on modes, the NRR mechanisms for all three possible routes were computed and are are presented in Fig. 4. Although, the parallel mode of $\mathrm{N}_{2}$ adsorption is more exergonic than the the perpendicular mode, and we expect the enzymatic route to be favoured over the distal or alternating route, the limiting potential for the NRR on the $\mathrm{B}_{\mathrm{SAC}} @ \mathrm{Mo}_{2} \mathrm{C}-\mathrm{Mo}_{\text {vac }}$ catalyst was

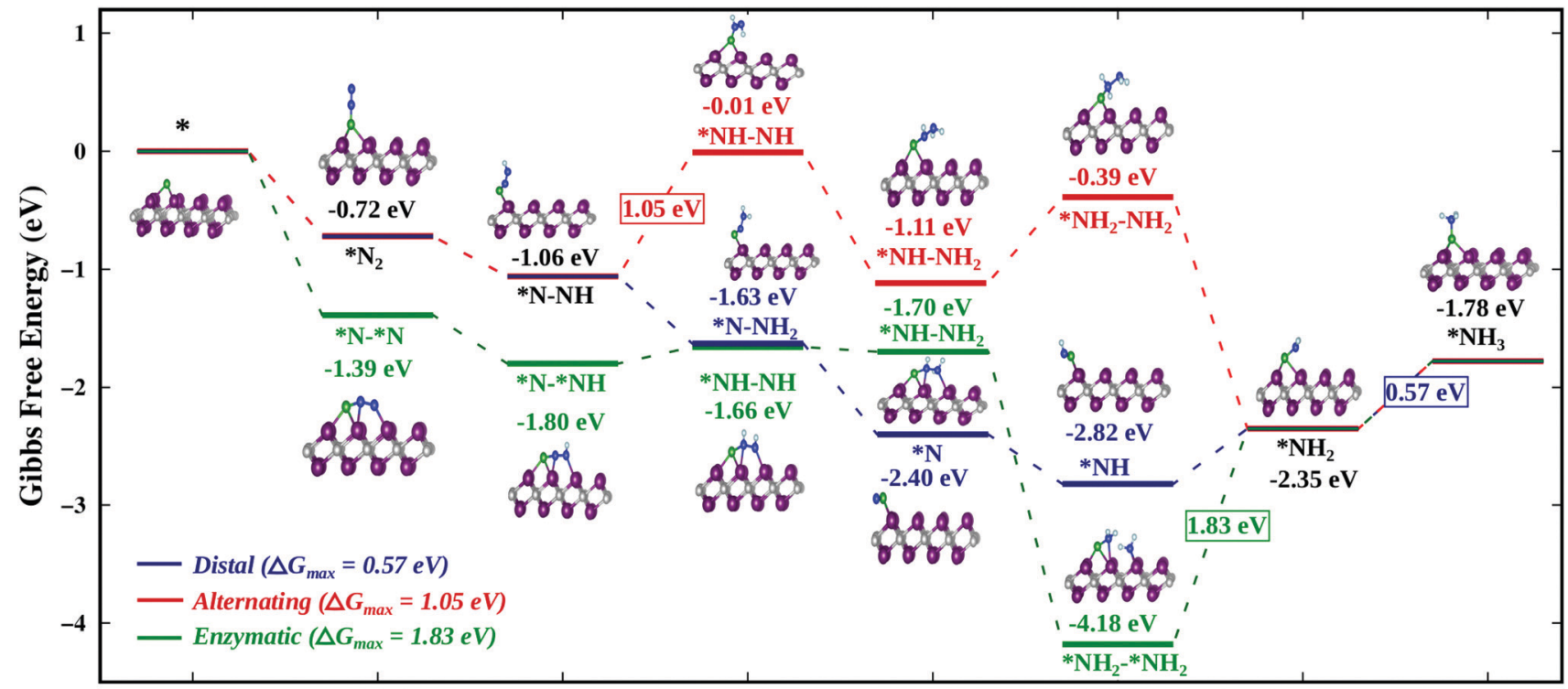

Free Energy Diagram of NRR on $\mathrm{B}_{\mathrm{SAC}} @ \mathrm{Mo}_{2} \mathrm{C}-\mathrm{Mo}_{\text {vac }}$ substrate

Fig. 4 Free energy profile of the nitrogen reduction reaction via the distal, alternating and enzymatic routes on the $\mathrm{B}_{\mathrm{SAC}} @ \mathrm{Mo}_{2} \mathrm{C}-\mathrm{Mo}_{\mathrm{vac}} \mathrm{Catalyst}$. 
found to be $0.57 \mathrm{eV}\left({ }^{*} \mathrm{NH}_{2} \rightarrow{ }^{*} \mathrm{NH}_{3}\right)$ for the distal, $1.05 \mathrm{eV}$ $\left({ }^{*} \mathrm{~N}-\mathrm{NH} \rightarrow{ }^{*} \mathrm{NH}-\mathrm{NH}\right)$ for the alternating and $1.83 \mathrm{eV}\left({ }^{*} \mathrm{NH}_{2}-\right.$ ${ }^{*} \mathrm{NH}_{2} \rightarrow{ }^{*} \mathrm{NH}_{2}$ ) for the enzymatic route. The distal route, which involves the protonation of only one nitrogen atom to form the first ammonia molecule, can be seen to show downhill reaction steps until the fourth protonation step. The preference for the distal mode could be accounted for by less steric hindrance caused by subsequent protonation on the nitrogen atoms. It is interesting to note that the $\mathrm{B}_{\mathrm{SAC}} @ \mathrm{Mo}_{2} \mathrm{C}-\mathrm{Mo}_{\mathrm{vac}}$ catalyst shows a high affinity for capturing the ${ }^{*} \mathrm{NH}_{2}$ moiety as it can be found from the enzymatic route. The ${ }^{*} \mathrm{NH}_{2}-{ }^{*} \mathrm{NH}_{2}$ intermediate shows a highly exergonic adsorption with dissociation of the $\mathrm{N}-\mathrm{N}$ bond and the adsorption of one ${ }^{*} \mathrm{NH}_{2}$ on the Mo atom of the monolayer. Dissociating the $\mathrm{N}-\mathrm{N}$ bond would be the ultimate goal of the NRR, however, if the catalyst holds onto the ammonia molecule strongly, the effectiveness and applicability of the catalyst is restricted. As a result, the enzymatic route would be a highly unlikely and unfavoured route for reducing $\mathrm{N}_{2}$ molecules. A similar case of the high exergonic adsorption of the ${ }^{*} \mathrm{NH}_{2}{ }^{-*} \mathrm{NH}_{2}$ intermediate can be seen for the $\mathrm{B}_{\mathrm{SAC}} @ \mathrm{Mo}_{2} \mathrm{C}-$ $\mathrm{C}_{\mathrm{def}}$ catalyst (Fig. S6, ESI $\dagger$ ), wherein the limiting potentials for nitrogen reduction were found to be $1.42 \mathrm{eV}$ for the distal and alternating routes $\left({ }^{*} \mathrm{NH}_{2} \rightarrow{ }^{*} \mathrm{NH}_{3}\right)$ and $2.26 \mathrm{eV}$ for the enzymatic route $\left({ }^{*} \mathrm{NH}_{2}-{ }^{*} \mathrm{NH}_{2} \rightarrow{ }^{*} \mathrm{NH}_{2}\right)$. The limiting potentials and the corresponding potential determining steps on the above mentioned $\mathrm{B}_{\text {cat }} @ \mathrm{Mo}_{2} \mathrm{C}$ catalysts are summarised in Table 1.

While an exergonic adsorption of $\mathrm{N}_{2}$ is essential for the feasible capture of $\mathrm{N}_{2}$, it is not the only deciding factor for successful nitrogen reduction. There have been no accounts correlating dinitrogen adsorption to the efficacy of nitrogen reduction and the corresponding limiting potential. The exergonic free energy of $\mathrm{N}_{2}$ follows the order $\mathrm{B}_{\mathrm{SAC}} @ \mathrm{Mo}_{2} \mathrm{C}-\mathrm{Mo}_{\mathrm{vac}}>$ $\mathrm{B}_{\mathrm{SAC}} @ \mathrm{Mo}_{2} \mathrm{C}-\mathrm{C}_{\mathrm{def}}>\mathrm{B}_{\mathrm{SAC}} @ \mathrm{Mo}_{2} \mathrm{C}>\mathrm{B}_{\mathrm{DAC}} @ \mathrm{Mo}_{2} \mathrm{C}$, however the limiting potential of nitrogen reduction follows the order $\mathrm{B}_{\mathrm{SAC}} @ \mathrm{Mo}_{2} \mathrm{C}-\mathrm{C}_{\mathrm{def}}>\mathrm{B}_{\mathrm{SAC}} @ \mathrm{Mo}_{2} \mathrm{C}>\mathrm{B}_{\mathrm{DAC}} @ \mathrm{Mo}_{2} \mathrm{C}>\mathrm{B}_{\mathrm{SAC}} @$ $\mathrm{Mo}_{2} \mathrm{C}-\mathrm{Mo}_{\text {vac }}$. In order to correlate the $\mathrm{N}_{2}$ adsorption and the limiting potential, we probe into the electronic properties of the adsorbed $\mathrm{N}_{2}$ and $\mathrm{N}_{x} \mathrm{H}_{y}$ species via the Bader charges on the $\mathrm{B}$ atom and $\mathrm{N}$ atoms for all the $\mathrm{B}_{\text {cat }} @ \mathrm{Mo}_{2} \mathrm{C}$ catalysts as shown in Fig. 5. The N-atoms are seen to be negatively charged on all the $\mathrm{N}_{x} \mathrm{H}_{y}$ intermediates and tend to be more electron rich for subsequent reaction steps thereby making the protonation facile. While the differences in Bader charge on the $\mathrm{N}$-atoms

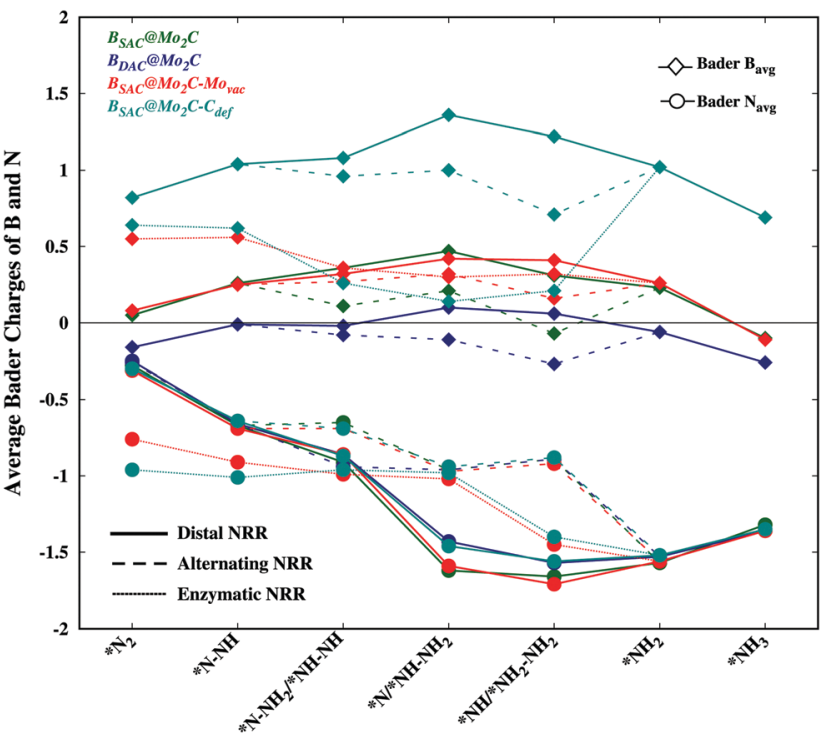

Fig. 5 Bader charges on $\mathrm{N}$ and $\mathrm{B}$ atom catalysts for $\mathrm{N}_{x} \mathrm{H}_{y}$ intermediates involved in the free energy diagram for the NRR on all the $\mathrm{B}_{\text {cat }}\left(\mathrm{aMO}_{2} \mathrm{C}\right.$ catalysts.

are minute for different catalysts, the charges on the B-atoms are prominent with less positive $\mathrm{B}$-atoms on the $\mathrm{B}_{\mathrm{DAC}} @ \mathrm{Mo}_{2} \mathrm{C}$, $\mathrm{B}_{\mathrm{SAC}} @ \mathrm{Mo}_{2} \mathrm{C}-\mathrm{Mo}_{\mathrm{vac}}$ and $\mathrm{B}_{\mathrm{SAC}} @ \mathrm{Mo}_{2} \mathrm{C}$ catalysts, followed by the $\mathrm{B}_{\mathrm{SAC}} @ \mathrm{Mo}_{2} \mathrm{C}-\mathrm{C}_{\mathrm{def}}$ catalyst. A highly positive B-atom on the corresponding $\mathrm{N}_{x} H_{y}$ intermediates would deplete the negative charge on the $\mathrm{N}$-atom, thereby restricting the protonation steps as seen in the case of $\mathrm{B}_{\mathrm{SAC}} @ \mathrm{Mo}_{2} \mathrm{C}-\mathrm{C}_{\mathrm{def}}$. Therefore, the $\mathrm{B}_{\mathrm{SAC}} @$ $\mathrm{Mo}_{2} \mathrm{C}-\mathrm{Mo}_{\mathrm{vac}}$ catalyst with strong $\mathrm{N}_{2}$ chemisorption captures the dinitrogen molecule effectively and the electron deficient $\mathrm{B}$ atom aids the protonation steps in the NRR, thus making it an attractive electrocatalyst with a limiting potential of $0.57 \mathrm{eV}$ and an overpotential of $0.41 \mathrm{eV}$. In contrast, the relatively high limiting potential of $1.10 \mathrm{eV}$ for $\mathrm{B}_{\mathrm{SAC}} @ \mathrm{Mo}_{2} \mathrm{C}$ in spite of the similar charges on the B-atoms can be accounted for by a less exergonic $\mathrm{N}_{2}$ adsorption as compared to $\mathrm{B}_{\mathrm{SAC}} @ \mathrm{Mo}_{2} \mathrm{C}-\mathrm{Mo}_{\mathrm{vac}}$. Additionally, $\mathrm{B}_{\mathrm{DAC}} @ \mathrm{Mo}_{2} \mathrm{C}$ with electron rich B-atoms shows a relatively higher limiting potential of $0.90 \mathrm{eV}$ owing to its less exergonic $\mathrm{N}_{2}$ adsorption. We further correlate our analogy to the first protonation step of the NRR, which is usually considered a crucial step in the NRR. It has been reported that a

Table 1 Gibbs free energies, $\Delta G(\mathrm{eV})$ of $\mathrm{N}_{2}$ adsorption, first protonation and rate determining step $\left(\Delta G_{\max }\right)$ and overpotential, $\eta$ for all routes of the NRR on the $\mathrm{B}_{\text {cat }} \mathrm{QMO}_{2} \mathrm{C}$ catalysts

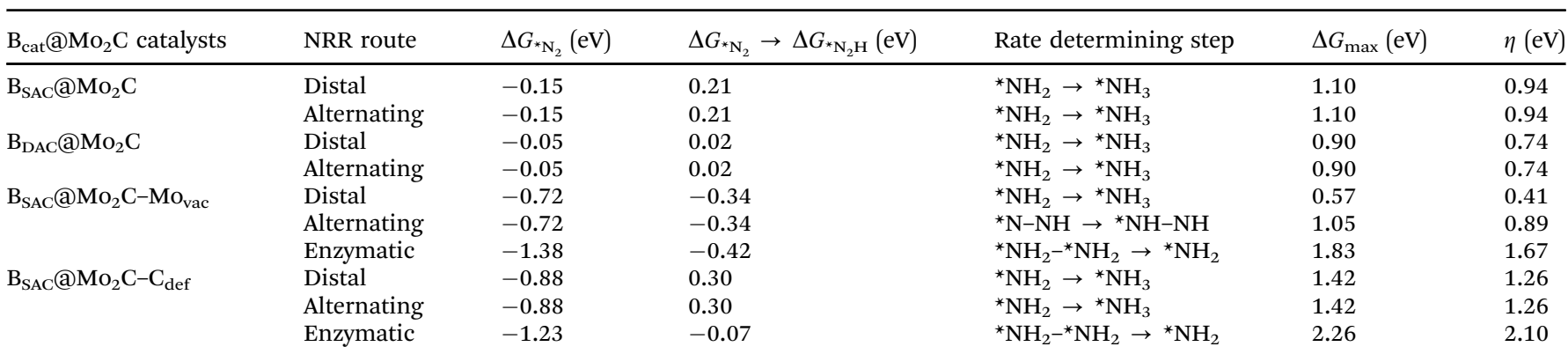


less endergonic or exergonic ${ }^{*} \mathrm{~N}_{2} \rightarrow{ }^{*} \mathrm{~N}_{2} \mathrm{H}$ step leads to a lower limiting potential for nitrogen reduction. Upon comparison of the free energies of the first protonation steps, the $\mathrm{B}_{\mathrm{cat}} @ \mathrm{Mo}_{2} \mathrm{C}$ catalysts with less endergonic free energies, i.e., $\mathrm{B}_{\mathrm{SAC}} @ \mathrm{Mo}_{2} \mathrm{C}-$ $\mathrm{Mo}_{\text {vac }}(-0.34 \mathrm{eV})$ and $\mathrm{B}_{\mathrm{DAC}} @ \mathrm{Mo}_{2} \mathrm{C}(0.02 \mathrm{eV})$ exhibit lower limiting potentials as compared to $\mathrm{B}_{\mathrm{SAC}} @ \mathrm{Mo}_{2} \mathrm{C}$ and $\mathrm{B}_{\mathrm{SAC}} @$ $\mathrm{Mo}_{2} \mathrm{C}-\mathrm{C}_{\mathrm{def}}$. This analogy holds true only for the distal and alternating routes wherein $\mathrm{N}_{2}$ has been adsorbed in the end-on mode. Our previous argument correlating $\mathrm{N}_{2}$ adsorption free energies and Bader charges is in agreement with the analogy of first protonation energies, and therefore can give insightful information on the mutual correlation between the free energies of the adsorption and electronic properties that directly govern the limiting potentials of the $\mathrm{NRR}$ on $\mathrm{B}_{\text {cat }} @ \mathrm{Mo}_{2} \mathrm{C}$ catalysts. Furthermore, the $\mathrm{B}_{\mathrm{SAC}} @ \mathrm{Mo}_{2} \mathrm{C}-\mathrm{Mo}_{\mathrm{vac}}$ catalyst with one Mo-vacancy is found to efficiently capture and accentuate the catalytic activity of the boron SAC with a very low overpotential of $0.41 \mathrm{eV}$ for the NRR. This study provides an indepth analysis of the electronic factors crucial for efficient $\mathrm{N}_{2}$ adsorption and reduction, and proposes the $\mathrm{B}_{\mathrm{SAC}} @ \mathrm{Mo}_{2} \mathrm{C}-\mathrm{Mo}_{\mathrm{vac}}$ catalyst as a potential candidate for the NRR.

\section{Conclusions}

In summary, a detailed and systematic DFT investigation has been carried out to analyse the efficacy of $\mathrm{N}_{2}$ adsorption and reduction on $\mathrm{B}_{\mathrm{cat}} @ \mathrm{Mo}_{2} \mathrm{C}$ monolayers. Our study identifies a metal-free boron anchored defective $\mathrm{Mo}_{2} \mathrm{C}$ monolayer with superior electrocatalytic activity for the NRR at $0.41 \mathrm{eV}$ on account of a more positive p-band center and the negative charge of boron SACs that implicitly stabilizes the intermediates along the energy profile of the NRR. The insights gained from this work can be implemented for further research towards the design of efficient B-atom based electrocatalysts for the nitrogen reduction reaction.

\section{Author contributions}

Ashakiran Maibam: calculation, methodology, investigation and analysis. Sailaja Krishnamurty and Manzoor Ahmad Dar: conceptualization and work design. All authors contributed equally to writing, reviewing and editing the manuscript.

\section{Conflicts of interest}

There are no conflicts of interest to declare.

\section{Acknowledgements}

A. M. acknowledges the CSIR for funding of the SRF (Senior Research Fellowship). M. A. D. acknowledges the Start-up research grant (SRG/2020/00654) from the SERB, India for financial support towards the completion of this work. The authors gratefully acknowledge the National Supercomputing Mission (NSM) for providing the computing resources of
'PARAM Brahma' at IISER Pune, which is implemented by C-DAC and supported by the Ministry of Electronics and Information Technology (MeitY) and the Department of Science and Technology (DST), Government of India.

\section{Notes and references}

1 N. Cherkasov, O. Ibhadon and P. Fitzpatrick, Chem. Eng. Process., 2015, 90, 24-33.

2 C. J. M. Ham, M. T. M. Koper and D. G. H. Hetterscheid, Chem. Soc. Rev., 2014, 43, 5183-5191.

3 J. W. Erisman, M. A. Sutton, J. Galloway, Z. Klimont and W. Winiwarter, Nat. Geosci., 2008, 1, 636-639.

4 A. Afif, N. Radenahmad, Q. Cheok, S. Shams, J. H. Kim and A. K. Azad, Renewable Sustainable Energy Rev., 2016, 60, 822-835.

5 G. Zheng, J. M. Yan and G. Yu, Small Methods, 2019, 3, 1900070.

6 X. Xue, R. Chen, C. Yan, P. Zhao, Y. Hu, W. Zhang, S. Yang and Z. Jin, Nano Res., 2019, 12, 1229-1249.

7 C. Tang and S.-Z. Qiao, Chem. Soc. Rev., 2019, 48, 3166-3180.

8 G. Qing, R. Ghazfar, S. T. Jackowski, F. Habibzadeh, M. M. Ashtiani, C.-P. Chen, M. R. Smith III and T. W. Hamann, Chem. Rev., 2020, 120, 5437-5516.

9 H. Tao, C. Choi, L.-X. Ding, Z. Jiang, Z. Han, M. Jia, Q. Fan, Y. Gao, H. Wang, A. W. Robertson, S. Hong, Y. Jung, S. Liu and Z. Sun, Chem, 2019, 5, 204-214.

10 Y. Yao, H. Wang, X.-Z. Yuan, H. Li and M. Shao, ACS Energy Lett., 2019, 4, 1336-1341.

11 Q. Qin, T. Heil, M. Antonietti and M. Oschatz, Small Methods, 2018, 2, 1800202.

12 K. Zhang, R. Guo, F. Pang, J. He and W. Zhang, ACS Sustainable Chem. Eng., 2019, 7, 10214-10220.

13 H. Zhao, D. Zhang, H. Li, W. Qi, X. Wu, Y. Han, W. Cai, Z. Wang, J. Lai and L. Wang, Adv. Energy Mater., 2020, 10, 2002131.

14 G. Deng, T. Wang, A. A. Alshehri, K. A. Alzahrani, Y. Wang, H. Ye, Y. Luo and X. Sun, J. Mater. Chem. A, 2019, 7, 21674-21677.

15 S. L. Foster, S. I. Perez Bakovic, R. D. Duda, S. Maheshwari, R. D. Milton, S. D. Minteer, M. J. Janik, J. N. Renner and L. F. Greenlee, Nat. Catal., 2018, 490-500.

16 B. M. Hoffman, D. Lukoyanov, Z.-Y. Yang, D. R. Dean and L. C. Seefeldt, Chem. Rev., 2014, 114, 4041-4062.

17 X. Guo, X. Wan and J. Shui, Cell Rep. Phys. Sci., 2021, 2, 100447.

18 K. C. MacLeod and P. L. Holland, Nat. Chem., 2013, 5, 559-565.

19 D. K. Yesudoss, G. Lee and S. Shanmugam, Appl. Catal., B, 2021, 287, 119952.

20 L. Han, X. Liu, J. Chen, R. Lin, H. Liu, F. Lü, S. Bak, Z. Liang, S. Zhao, E. Stavitski, J. Luo, R. R. Adzic and H. L. Xin, Angew. Chem., Int. Ed., 2019, 58, 2321-2325.

21 Q. Li, S. Qiu, C. Liu, M. Liu, L. He, X. Zhang and C. Sun, J. Phys. Chem. C, 2019, 123, 2347-2352. 
22 A. Maibam, T. Govindaraja, K. Selvaraj and S. Krishnamurty, J. Phys. Chem. C, 2019, 123, 27492-27500.

23 L. R. Johnson, S. Sridhar, L. Zhang, K. D. Fredrickson, A. S. Raman, J. Jang, C. Leach, A. Padmanabhan, C. C. Price, N. C. Frey, A. Raizada, V. Rajaraman, S. A. Saiprasad, X. Tang and A. Vojvodic, ACS Catal., 2020, 10, 253-264.

24 B. H. R. Suryanto, D. Wang, L. M. Azofra, M. Harb, L. Cavallo, R. Jalili, D. R. G. Mitchell, M. Chatti and D. R. MacFarlane, ACS Energy Lett., 2019, 4, 430-435.

25 B. Zhang, J. Zhou, S. R. Elliott and Z. Sun, J. Mater. Chem. A, 2020, 8, 23947-23954.

26 Q. Li, L. He, C. Sun and X. Zhang, J. Phys. Chem. C, 2017, 121, 27563-27568.

27 P. Ou, X. Zhou, F. Meng, C. Chen, Y. Chen and J. Song, Nanoscale, 2019, 11, 13600-13611.

28 T. Yang, T. T. Song, J. Zhou, S. Wang, D. Chi, L. Shen, M. Yang and Y. P. Feng, Nano Energy, 2020, 68, 104304.

29 L. Zhang, X. Ji, X. Ren, Y. Ma, X. Shi, Z. Tian, A. M. Asiri, L. Chen, B. Tang and X. Sun, Adv. Mater., 2018, 30, 1800191.

30 X. Zhai, L. Li, X. Liu, Y. Li, J. Yang, D. Yang, J. Zhang, H. Yan and G. Ge, Nanoscale, 2020, 12, 10035-10043.

31 C. Ma, X. Yan, H. He, B. Liu and S. Yan, Sustainable Energy Fuels, 2021, 5, 2415-2418.

32 K. Ba, G. Wang, T. Ye, X. Wang, Y. Sun, H. Liu, A. Hu, Z. Li and Z. Sun, ACS Catal., 2020, 10, 7864-7870.

33 K. P. Ramaiyan, S. Ozden, S. Maurya, D. Kelly, S. K. Babu, A. Benavidez, F. G. Garzon, Y. S. Kim, C. R. Kreller and R. Mukundan, J. Electrochem. Soc., 2020, 167, 044506.

34 B. Zhang, J. Zhou, S. R. Elliott and Z. Sun, J. Mater. Chem. A, 2020, 8, 23947-23954.

35 S. Qi, Y. Fan, L. Zhao, W. Li and M. Zhao, Appl. Surf. Sci., 2021, 536, 147742.
36 X. Yang, C. Shang, S. Zhou and J. Zhao, Nanoscale Horiz., 2020, 5, 1106-1115.

37 Y. Liu, L. Gu, X. Zhu, Q. Zhang, T. Tang, Y. Zhang, Y. Li, J. Bao, Z. Dai and J.-S. Hu, J. Mater. Chem. A, 2020, 8, 8920-8926.

38 X. Ren, J. Zhao, Q. Wei, Y. Ma, H. Guo, Q. Liu, Y. Wang, G. Cui, A. M. Asiri, B. Li, B. Tang and X. Sun, ACS Cent. Sci., 2019, 5, 116-121.

39 Y. Ma, T. Yang, H. Zou, W. Zang, Z. Kou, L. Mao, Y. Feng, L. Shen, S. J. Pennycook, L. Duan, X. Li and J. Wang, Adv. Mater., 2020, 32, 2002177.

40 A. Maibam and S. Krishnamurty, J. Colloid Interface Sci., 2021, 600, 480-491.

41 X. Liu, X. Jiao, Y. Zheng and S.-Z. Qiao, ACS Catal., 2020, 10, 1847-1854.

42 C. Liu, Q. Li, C. Wu, J. Zhang, Y. Jin, D. R. MacFarlane and C. Sun, J. Am. Chem. Soc., 2019, 141, 2884-2888.

43 S. Xiao, F. Luo, H. Hua and Z. Yang, Chem. Commun., 2020, 56, 446-449.

44 L. Shi, Q. Li, C. Ling, Y. Zhang, Y. Ouyang, X. Baia and J. Wang, J. Mater. Chem. A, 2019, 7, 4865-4871.

45 C. Ling, X. Niu, Q. Li, A. Du and J. Wang, J. Am. Chem. Soc., 2018, 140, 14161-14168.

46 G. Kresse and J. Furthmuller, Comput. Mater. Sci., 1996, 6, 15-50.

47 J. P. Perdew, K. Burke and M. Ernzerhof, Phys. Rev. Lett., 1996, 77, 3865-3868.

48 S. Grimmea, J. Antony, S. Ehrlich and H. Krieg, J. Chem. Phys., 2010, 132, 154104.

49 J. K. Nørskov, J. Rossmeisl, A. Logadottir, L. Lindqvist, J. R. Kitchin, T. Bligaard and H. Jónsson, J. Phys. Chem. B, 2004, 108, 17886-17892. 